\title{
Alterações histológicas e imunoistoquímicas em pâncreas de ratos normais e diabéticos tratados com Syzygium cumini
}

\author{
Histological and immunohistochemical alterations in the pancreas of normal \\ and diabetic rats treated with Syzygium cumini
}

\section{Deila Rosely Carneiro Schossler ${ }^{1}$ Cinthia Melazzo Mazzanti ${ }^{2}$ Sônia Cristina Almeida da Luz ${ }^{3}$ Andreane Filappi ${ }^{4}$ Danívia Prestes $^{4}$ Aron Ferreira da Silveira ${ }^{5}$ Marcelo Cecim $^{6}$}

\section{RESUMO}

Avaliou-se o efeito da administração oral do extrato da casca de Syzygium cumini sobre o pâncreas de ratos normais e diabéticos. Os animais foram divididos em grupo controle $(C)$, controle tratado $(C T)$, diabético controle $(D C)$ e diabético tratado (DT). Os tratados receberam dose diária de $1 \mathrm{~g} \mathrm{~kg}^{-1}$ de peso vivo, durante 30 dias. Os animais foram submetidos à eutanásia e o pâncreas retirado para análise histológica e imunoistoquímica para insulina. Neste estudo observou-se uma diminuição $(P<0,001)$ no número e tamanho das ilhotas pancreáticas, alteração na sua citoarquitetura e diminuição $(P<0,0001)$ do número de células com marcação positiva para insulina nos animais diabéticos em relação aos não diabéticos. Não foi observada diferença entre os animais dos grupos DC e DT e entre os dos grupos $C$ e CT. Estes resultados indicam que o extrato da casca de Syzygium cumini não afeta o número, o tamanho e a citoarquitetura das ilhotas pancreáticas e não promove um aumento no número de células $\beta$ em animais tratados com a planta.

Palavras-chave: Syzygium cumini, diabetes, histologia, imunoistoquímica.

\section{ABSTRACT}

This study verified the effect of Syzygium cumini bark extract on the pancreas of normal and diabetic rats. The animals were allocated into four groups, control $(C)$, treated control (TC), diabetic control (DC) and treated diabetic (TD). An aqueous extract from Syzygium cumini bark, was given by gavage in a daily dose of $1 \mathrm{~g} \mathrm{~kg}^{-1}$ of body weight. After a thirty day period, the animals were euthanized and the pancreas taken to imunno-histochemical analysis. A significant decrease in the number and size of islets, citoarchitectural alterations, as well as a severe decrease in the number of positive cells in diabetic animals ( $p<0.0001)$ was observed. However, was noticed a no significant difference neither between DC and DT nor C and CT groups. These results indicate that the Syzygium cumini bark extract does not affect significantly the number, size and citoarchitecture of islets, and, it also does not lead to an increase in $\beta$ cell number in animals treated with the plant extract.

Key words: Syzygium cumini, diabetes, histology, imunnohistochemistry.

\section{INTRODUÇÃO}

O Syzygium cumini (sinonímias: Syzygium jambolanum, Eugenia jambolana, Syzygium jambos) é uma planta popularmente utilizada no tratamento da diabetes melito insulino dependente (DMID). A casca, o fruto, a semente e a folha dessa planta são utilizados no tratamento da diabetes e preparados como extrato aquoso ou decocção, extrato etanólico ou suco da planta crua ( PEPATO et al., 2001).

As alterações observadas no pâncreas de animais diabéticos caracterizam-se por diminuição das células beta $(\beta)$ e distorção da citoarquitetura das ilhotas, além de distribuição irregular de outras células pancreáticas. Devido à intensa estimulação pelas quais as células $\beta$ estão sujeitas, elas raramente sofrem mitose (GEPTS \& LECOMPTE, 1981).

A infiltração linfocítica nas ilhotas, denominada de insulite, é considerada uma lesão específica encontrada no pâncreas de pacientes

\footnotetext{
${ }^{1}$ Médico Veterinário,' Dr, Professor Adjunto, Departamento de Morfologia, Universidade Federal de Santa Maria (UFSM).

${ }^{2}$ Médico Veterinário, Programa de Pós-graduação em Bioquímica, Universidade Federal do Rio Grande do Sul (UFRGS).

${ }^{3}$ Médico, Professor Auxiliar, Departamento de Morfologia, UFSM.

${ }^{4}$ Médico Veterinário, Programa de Pós-graduação em Medicina Veterinária, UFSM.

${ }^{5}$ Médico Veterinário, Dr, Prof. Titular, Departamento de Morfologia, UFSM.

${ }^{6}$ Médico Veterinário, PhD, Professor Adjunto, Departamento de Clínica Grande Animais, UFSM. Santa Maria, RS, Brasil. CEP 97105900. E-mail: mcecim@hcv.ufsm.br Autor para correspondência.
} 
diabéticos, como os linfócitos são atraídos pela presença de antígenos nas células $\beta$, essa pode ser a causa da destruição progressiva das células em pacientes diabéticos (KESSLER et al., 1999). Segundo GEPTS \& LECOMPTE (1981), a infiltração pode consistir de apenas poucas células, podendo escapar da detecção histológica.

O presente trabalho teve como objetivo verificar a influência do extrato da casca de Syzygium cumini no tamanho, na citoarquitetura, no número de células $\beta$ e na presença de fibroblastos e células mononucleares nas ilhotas pancreáticas de ratos normais e diabéticos.

\section{MATERIAL E MÉTODOS}

O estudo foi realizado em ratas adultas da linhagem Wistar, com pesos entre 180 e $300 \mathrm{~g}$, provenientes do Biotério Central da Universidade Federal de Santa Maria (UFSM). Foi oferecido aos animais dieta sólida ${ }^{\mathrm{a}}$ e hídrica ad libitum. Os animais passaram por um período de adaptação de 10 dias antes do início do experimento.

As cascas do caule de Syzygium cumini foram coletadas em maio de 2001, no município de Santa Maria, RS. A planta foi identificada e registrada no herbário de plantas medicinais e tóxicas do Departamento de Farmácia Industrial da UFSM, pela exsicata de número 160. O material vegetal (casca do caule) de Syzygium cumini foi desidratado em estufa à temperatura de $50^{\circ} \mathrm{C}$, e moído em moinho de Wiley e dele fez-se a extração a frio, utilizando-se o etanol como solvente. $\mathrm{O}$ extrato bruto foi obtido após a evaporação do solvente em rotavapor com rendimento de $10 \%$ do peso $(4100 \mathrm{~g})$ da casca do caule.

Para a indução da DMID foram utilizados 150 animais. Após permanecerem em jejum por 24 horas, administrou-se aloxano ${ }^{\mathrm{b}}$ (diluído a $2 \% \mathrm{em}$ solução de citrato de sódio $0,05 \mathrm{M}, \mathrm{pH} 4,5$ ) na dose única de $150 \mathrm{mg} / \mathrm{kg}$, via intraperitoneal. Seis horas da indução, os animais receberam glicose a $10 \%$ ad libitum como única fonte de alimentação. Decorridos 15 dias determinou-se a glicose sangüínea e somente os animais com glicemia de jejum superior a 180mg/ $\mathrm{dL}$ foram considerados diabéticos e selecionados para o experimento.

Nos grupos 1 , controle $(C ; n=11)$ e 2 , controle tratado $(\mathrm{CT} ; \mathrm{n}=9)$ foram utilizados animais não induzidos com aloxano. Os animais diabéticos foram divididos, de forma aleatória em grupo 3, diabético controle (DC; $n=10$ ) e grupo 4, diabético tratado (DT; $n=9)$. Os grupos 1 e 3 receberam diariamente $2 \mathrm{~mL}$ de água destilada, e os grupos 2 e 4 receberam diariamente o extrato da casca de Syzygium cumini na dose de $1 \mathrm{~g} / \mathrm{kg}$ de peso vivo através de uma sonda oroesofágica.

Ao final de um período de tratamento de 30 dias os animais foram submetidos à eutanásia. Após a abertura da cavidade abdominal, o pâncreas avaliado macroscopicamente, foi coletado e fixado em formol tamponado à temperatura ambiente por 24 horas. Posteriormente, os órgãos emblocados em parafina, foram submetidos a cortes seriados $(7 \mu \mathrm{m})$, escolhendose aleatoriamente três cortes, os quais foram fixados em lâminas previamente preparadas com organosilano.

As secções foram imunocoradas para insulina, utilizando a técnica de imunoperoxidase, método da estreptoavidina-biotina proposto por PEINADO et al. (1996).

A avaliação semi-quantitativa foi feita utilizando-se um micróscopio Olympus e realizandose a contagem do número de ilhotas por pâncreas em aumento de 100X. Observaram-se individualmente as ilhotas em aumento de 400X para contagem dos núcleos das células positivas (marcação para insulina) e células negativas. Foram observadas a citoarquitetura e a presença de fibroblastos e células mononucleares nas ilhotas, sendo realizada a morfometria com régua micrometrada em aumento de $100 \mathrm{X}$ no mesmo microscópio.

Realizou-se a análise estatística (análise de variância) para número e tamanho de ilhotas por pâncreas e número de células positivas e negativas para insulina por ilhota pancreática e, usou-se o teste de comparações múltiplas de Tukey-Kramer.

\section{RESULTADOS E DISCUSSÃO}

Todos os animais apresentaram pâncreas com características macroscópicas normais. Histologicamente, foi demonstrado que nos animais dos grupos DC e DT houve redução no tamanho e número das ilhotas pancreáticas $(\mathrm{P}<0,001)$, acompanhada de diminuição no número de células $\beta$ $(\mathrm{P}<0,0001)$ em relação ao grupo $\mathrm{C}$ (Tabela 1). Não houve diferença entre os animais dos grupos C e CT e entre os dos grupos DC e DT. Estes resultados confirmam os de DUMM et al. (1995), que observaram marcada redução no número, tamanho e distorção da citoarquitetura das ilhotas de animais diabéticos em decorrência da diminuição do número de células $\beta$.

Nos animais dos grupos C e CT foi observado um arranjo clássico das células nas ilhotas pancreáticas (Figura 1A e 1B). As células $\beta$ (células positivas) ocupavam posição central e as outras células endócrinas (células negativas), posição periférica, 
Tabela 1 - Número, tamanho, células positivas (+) e negativas (-) das ilhotas pancreáticas de ratos normais e diabéticos tratados com o extrato da casca de Syzygium cumini durante 30 dias.

\begin{tabular}{lllll}
\hline & \multicolumn{3}{c}{ Ilhotas pancreáticas } \\
\hline Grupo & Número & Tamanho $(\mu)$ & Célula $(+)$ & Célula $(-)$ \\
\hline Controle $(\mathrm{C}=11)$ & $8,4 \pm 0,50 \mathrm{a}$ & $107,84 \pm 2,07 \mathrm{a}$ & $86,88 \pm 2,72 \mathrm{a}$ & $22,59 \pm 0,53$ \\
Controle tratado $(\mathrm{CT}=9)$ & $8,4 \pm 0,24 \mathrm{a}$ & $105,72 \pm 2,37 \mathrm{a}$ & $85,02 \pm 4,73 \mathrm{a}$ & $22,45 \pm 0,92$ \\
Diabético controle $(\mathrm{DC}=10)$ & $3,5 \pm 0,26 \mathrm{~b}$ & $48,92 \pm 3,31 \mathrm{~b}$ & $1,77 \pm 0,17 \mathrm{~b}$ & $23,26 \pm 2,28$ \\
Diabético tratado $(\mathrm{DT}=9)$ & $3,3 \pm 0,33 \mathrm{~b}$ & $43,89 \pm 3,51 \mathrm{~b}$ & $2,05 \pm 0,20 \mathrm{~b}$ & $25,82 \pm 3,65$ \\
\hline
\end{tabular}

Os valores representam as médias \pm erro padrão da média (EPM). Letras diferentes na mesma coluna indicam diferenças $(\mathrm{P}<0,001)$ entre os valores.

semelhante ao que foi observado por ELAYAT et al. (1995) e TANIYAMA et al. (1999). Nos animais diabéticos observou-se distribuição irregular das células positivas (Figura 1C e 1D), sem que houvesse arranjo periférico das células negativas como descrito por BERNARD et al. (1998).

Os resultados obtidos demonstraram que a utilização do extrato aquoso da casca de Syzygium cumini na dose de $1 \mathrm{~g} / \mathrm{kg}$ não promoveu efeito regenerativo no tecido das ilhotas pancreáticas dos animais diabéticos tratados.

Neste estudo foi comprovada a destruição seletiva das células $\beta$ causada pelo aloxano descrita por ZAFIROVA et al. (1991), DUMM et al. (1994) e KESSLER et al. (1999). Praticamente todas as células $\beta$ foram destruídas confirmando os estudos realizados por MATHEUS \& LEITER (1999), DREW et al. (2000) e PESCHKE et al. (2000). Os animais dos grupos DC e DT apresentaram em torno de 1,91 células positivas/ilhota e, nos animais dos grupos C e CT a média foi de 85,95 células positivas/ilhota.

Não foi observado aumento no número de células $\beta$ nos animais diabéticos. Segundo BERNARD et al. (1998), as células $\beta$ possuem grande capacidade intrínseca de se adaptarem às alterações funcionais, sendo a glicose o regulador dessa plasticidade celular pancreática. Em um estudo realizado por PIPELEERS \& VAN DE WINKEL (1986), o grau de destruição das células $\beta$ pancreáticas provocado pelo aloxano in vitro foi reduzido em $80 \%$ pela adição de glicose ao meio. Assim, a ação do Syzygium cumini poderia ser semelhante ao da glicose, regulando essa plasticidade, porém a dose utilizada neste experimento pode não ter sido suficiente para induzir este mecanismo regenerador.

Outros fatores devem ser levados em consideração para explicar o não efeito do extrato da casca. O tempo de tratamento de 30 dias, pode ter sido insuficiente para produzir o efeito esperado, pois segundo PEPATO et al. (2001), a eficácia da planta está relacionada com tratamento prolongado.

De acordo com PRINCE et al. (1998) e GROVER et al. (2000), o efeito anti-hiperglicêmico dessa planta dependente da dose do agente diabetogênico e do grau de destruição das células $\beta$. Os animais deste experimento apresentavam diabetes severa (glicose plasmática maior que $400 \mathrm{mg} / \mathrm{dL}$ ) e reduzido número de células funcionais (média de 3 células/ilhota), aspectos que dificultariam a ação da planta.

Foi observado aumento das células negativas nos animais dos grupos DC e DT, porém o aumento não foi significativo em relação ao grupo $\mathrm{C}$, concordando com estudos realizados por DUMM et al. (1994). Essas alterações exibidas na síndrome diabética ainda não foram compreendidas. Sugere-se a existência de um sistema de controle parácrino que envolva a regulação da secreção hormonal na ilhota, ocorrendo uma interligação entre as células pancreáticas onde qualquer alteração de uma célula afeta o funcionamento das demais (DUMM et al., 1995). Este aumento pode estar relacionado à queda na produção de insulina, pois segundo DUMM et al. (1994), a insulina funciona inibindo a secreção de glucagon e não havendo insulina as células alfa $(\alpha)$ aumentam a sua produção e tornam-se hiperplásicas.

Neste estudo foi verificado maior quantidade de fibroblastos e vacuolização nas ilhotas dos animais diabéticos, porém não se observou a presença de células mononucleares fagocitárias (insulite), concordando com o estudo realizado por ZAFIROVA et al. (1991). KESSLER et al. (1999) afirmaram ser a insulite uma lesão específica da diabetes, mas segundo esses autores muitas vezes o número de células mononucleares apresentou-se pequeno, não sendo detectado em colorações rotineiras, tornando-se necessário a utilização de 


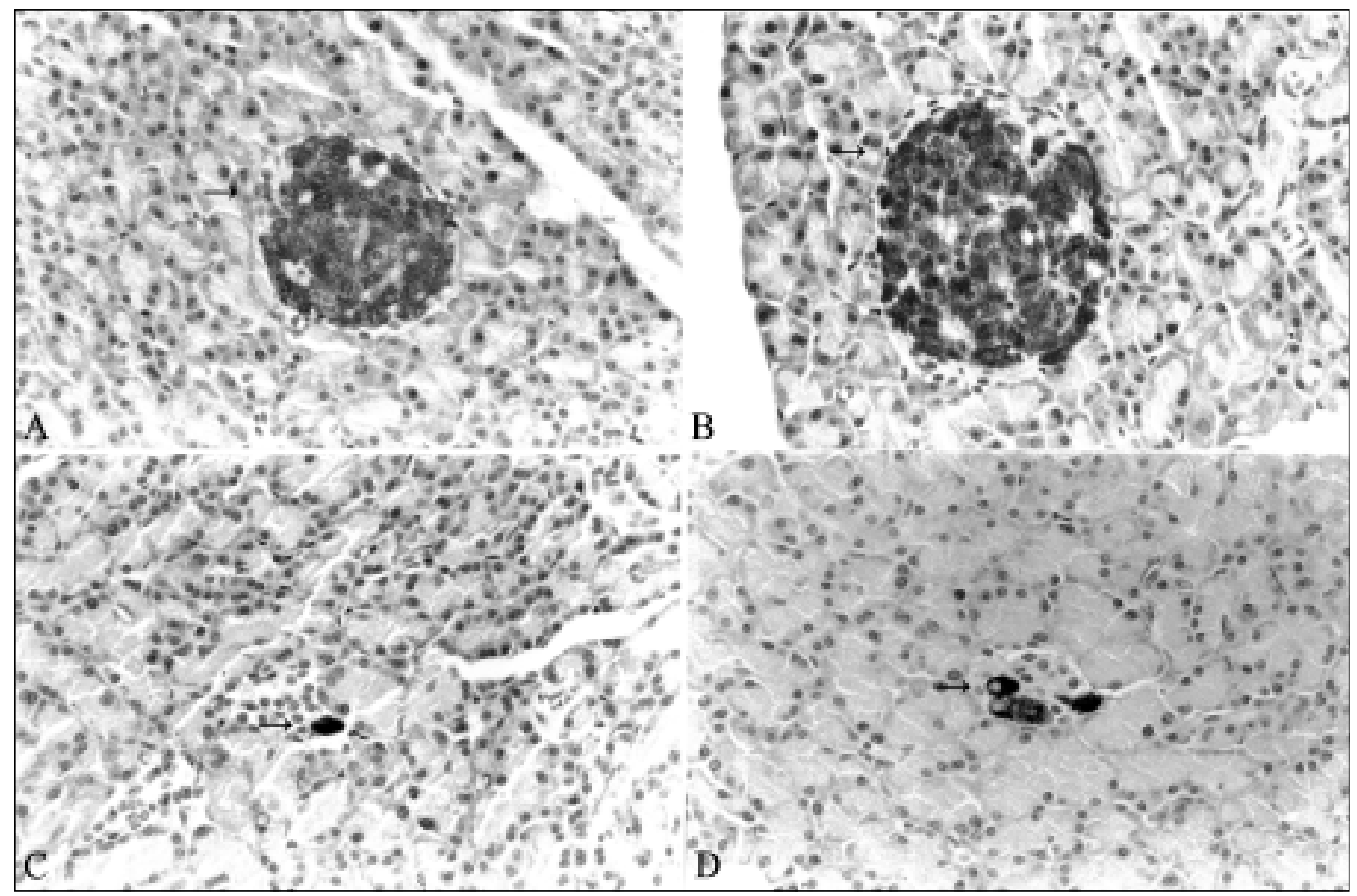

Figura 1 - Ilhotas pancreáticas com células b imunocoradas para insulina (indicadas pelas setas). Em A, verifica-se a ilhota de um animal controle e em B, nota-se a ilhota de um animal controle tratado. Em C, observa-se a ilhota de um animal diabético controle e em D, verifica-se a ilhota de um animal diabético tratado (x400)

técnicas de imunoistoquímica para a detecção específica dessas células.

\section{CONCLUSÕES}

Com base nos resultados obtidos neste estudo pode-se concluir que o extrato da casca de Syzygium cumini, na dose de $1 \mathrm{~g} / \mathrm{kg}$ e no período de 30 dias, não afeta o número, o tamanho e a citoarquitetura das ilhotas e não promove aumento no número de células $\beta$ de animais tratados com a planta. Também não reduz a presença de células mononuclerares e fibroblastos nas ilhotas pancreáticas.

\section{FONTES DE AQUISIÇÃO}

a- LAB, Alisul Ind. Alimentos Ltda, São Leopoldo, RS b- ALLOXAN MONOHYDRATE, Sigma-Aldrich Inc, St Louis, M.

\section{REFERÊNCIAS BIBLIOGRÁFICAS}

BERNARD, C. et al. Pancreatic $\beta$-cell regeneration after 48$\mathrm{h}$ glucose infusion in mildly diabetcs rats is not correlated with functional improvement. Diabetes, v.47, n.1, p.1058-1065, 1998.

DREWS, G. et al. Contrasting effect of alloxan on islets and single mouse pancreatic beta-cells. Biochem J, v.1, n.352, p.398397, 2000.

DUMM, C.L.A.G. et al. Quantitative immunocytochemical study of islet cell population in diabetic calmodulintransgenic mice. Virchows Archiv, v.425, n.1, p.73-77, 1994.

Quantitative immunohistochemical changes in the endocrine pancreas of nonobese diabetic (NOD) mice. Pancreas, v.11, n.4, p.396-401, 1995.

ELAYAT, A.A. et al. Immunocytochemical and morphormetric study of the rat pancreatic islets. J Anat, v.186, n.1, p.629-637, 1995.

GEPTS, W.; LECOMPTE, P.M. The pancreatic islet in diabetes. Am J Med, v.70, n.1, p.105-113, 1981.

GROVER, J.K. et al. Anti-hyperglicemic effect of Eugenia jambolana and tinospora cordifolia in experimental diabetes and their effects on key metabolic enzymes involved in carbohydrate metabolism. J Ethnopharmacol, v.73, n.3, p.461-470, 2000.

KESSLER, J. et al. Relationship between the histopatology of 
the endocrine-exocrine pancreas parenchyma and beta-cell function in the chinese hamster CHIG/ HAN subline. Pancreas, v.19, n.1, p.89-97, 1999.

MATHEUS, C.E.; LEITER, E.H. Constitutive differences in antioxidant defense status distinguish alloxan-resistant and alloxan-susceptible mice. Free Radic Biol Med, v.27, n.3, p.449-455, 1999

PEINADO, M.A. et al. Avances em immunocitoquímica y técnicas Relacionadas. Jaén : Gráfica la paz, 1996. 401p.

PESCHKE, E. et al. "Classical" and "new" diabetogenscompararison of their effects on isolated rat pancreatic islet in vitro. Cell Mol Life Sci, v.57, n.1, p.158-164, 2000.

PEPATO, M.T. et al. Lack of antidiabetic effect of Eugenia jambolana leaf decoction on rat streptozotocin diabetes. Braz J
Med Biol Res, v.34, n.1, p.389-395, 2001.

PIPELLERS, D.; VAN DE WINKEL, M. Pancreatic $\beta$ cells posses defense mechanisms against cell-especifc toxicity. Proc Natl Acad Sci, v.83, n.1, p.5267-5271, 1986.

PRINCE, P.S.M. et al. Hipoglicemic activity of Syzygium cumini seeds: effect on lipid peroxidation in alloxan diabetic rats. $\mathbf{J}$ Ethnopharmacol, v.61, n.1, p.1-7, 1998.

TANIYAMA, $H$. et al. Histopathological and immunohistochemical analysis of the endocrine and exocrine pancreas in twelve cattle with insulin-dependent diabetes mellitus (IDDM). J Vet Med Sci, v.61, n.7, p.803-810, 1999.

ZAFIROVA, M. et al. Morphological characteristics of endocrine pancreas in alloxan diabetes after cyclosporin A adminstration. Cell Mol Biol, v.37, n.6, p.585-596, 1991. 